\title{
Geologia
}

\section{Avaliação da Suscetibilidade a Processos Erosivos e Movimentos de Massa: Decisão Multicriterial Suportada em Sistemas de Informações Geográficas}

\author{
Luiz Carlos Pittol Martini' (Imartini@cca.ufsc.br), Antonio Ayrton Auzani Uberti', \\ Luiz Fernando Scheibe², Jucinei José Comin', Marcelo Accioly Teixeira de Oliveira² \\ 'Departamento de Engenharia Rural - Centro de Ciências Agrárias - UFSC \\ Rod. Admar Gonzaga 1346, CEP 88034-001, Florianópolis, SC, BRA \\ ${ }^{2}$ Departamento de Geociências - Centro de Filosofia e Ciências Humanas - UFSC, Florianópolis, SC, BRA
}

Recebido em 06 de dezembro de 2005; aceito em 10 de julho de 2006

Palavras-chave: erosão, movimentos de massa, avaliação multicritério.

\section{RESUMO}

Este trabalho apresenta um conjunto de procedimentos adotados na avaliação da suscetibilidade a processos erosivos e movimentos de massa na área de influência direta da usina hidrelétrica Quebra-Queixo, localizada no rio Chapecó, Santa Catarina. Para essa avaliação, empregaram-se recursos de decisão multicriterial suportada em Sistema de Informações Geográficas (SIG). Para compor a decisão multicriterial foram selecionados os critérios relevo, solo e cobertura vegetal, os quais foram subdivididos em onze fatores predominantes. Na associação dos fatores utilizou-se o método da combinação linear ponderada, com pesos e escores atribuídos por consenso técnico. O principal resultado obtido na aplicação dos procedimentos foi um mapa temático com a distribuição espacial das classes de suscetibilidade a processos erosivos e movimentos de massa no entorno do reservatório.

Keywords: soil erosion, mass movements, multi-criteria evaluation.

\begin{abstract}
The paper presents a set of erosion and mass movements susceptibility assessment procedures applied to the area of direct influence of the Quebra-Queixo hydroelectric power plant, located on the Chapecó river, Santa Catarina state, Brazil. The susceptibility assessment was based on the use of multi-criteria decision supported by a GIS. For the composition of the multi-criteria decision relief, soil and vegetation cover criteria were used, and were divided into eleven predominant factors. The weighted linear combination method was used in the association of factors, with weights and scores attributed to the method through technical consensus. The main result was a thematic map containing the spatial distribution of the erosive and mass movements susceptibility classes for the hydroelectric power plant’s surroundings.
\end{abstract}




\section{INTRODUÇÃO}

A erosão é um processo natural que resulta em transporte de massa devido à dinâmica superficial das encostas. Em grande parte acelerada por atividades antrópicas, a erosão é acionada por ventos e chuvas e a magnitude do processo é diretamente influenciada por fatores de solo, relevo e cobertura vegetal, principalmente. Em função dos efeitos na superfície, normalmente a erosão do solo é chamada de laminar, em ravinas ou em voçorocas, formadas em decorrência do arraste de partículas em taxas variáveis, mas com efeitos duradouros sobre a paisagem, modificando o relevo e os continentes, como no caso da erosão geológica, ou podendo atingir taxas de transporte muito acentuadas em áreas agrícolas ou zonas urbanas com intensa mobilização de solos. Para distinção desse processo, Bigarella (2003) chama de movimento de massa o “deslocamento de grande volume de material (solo e rocha) vertente abaixo sob influência da gravidade, sendo desencadeado pela interferência direta de outros meios ou agentes independentes, como água, gelo ou ar”. De acordo com Augusto Filho (1993), os movimentos de massa relacionados às encostas podem ser agrupados em quatro grandes classes: rastejos, escorregamentos, quedas e corridas. Cada uma dessas classes, por sua vez, admite outras subdivisões, que determinam variadas classificações e terminologias, as quais não serão abordadas aqui. Para a finalidade deste trabalho, a classe de maior interesse é a que engloba os escorregamentos, pois esses fenômenos geológicos apresentam elevado potencial de dano aos reservatórios e estruturas de usinas hidrelétricas. Segundo Fernandes e Amaral (1996), os escorregamentos "se caracterizam por movimentos rápidos, de curta duração, com plano de ruptura bem definido, permitindo a distinção entre o material deslizado e aquele não movimentado”. Soares et al. (2002), de forma mais sucinta, tratam os escorregamentos como um tipo de movimento de solo e rocha, rápido e não fluidizado.

Além das notórias implicações às terras agricultáveis, a erosão do solo ocasiona transporte de sedimentos aos corpos hídricos, com conseqüências adversas como decréscimo da qualidade das águas e assoreamento de rios e reservatórios. Os movimentos de massa, particularmente os escorregamentos, podem ocasionar catástrofes ambientais e acidentes em regiões povoadas, resultando em impactos aos meios físico e biótico e muitas vezes ocasionando vítimas fatais e perdas econômicas de grande vulto.

Tendo em vista a inegável importância dos processos erosivos e dos escorregamentos, a avaliação das possibilidades ou riscos para ocorrência desses fenômenos é decisiva na gestão de terras agrícolas, nas obras de construção civil, no planejamento urbano e em empreendimentos que causam profunda alteração no meio. Com relação a este último item, o objetivo deste trabalho é apresentar o conjunto de procedimentos adotados na avaliação da suscetibilidade a processos erosivos e escorregamentos na área de influência direta da usina hidrelétrica Quebra-Queixo, situada no rio Chapecó entre os municípios de São Domingos e Ipuaçu (SC). Para esta avaliação, fez-se uso da decisão multicriterial, definida como um conjunto de procedimentos analíticos destinado à avaliação e combinação de componentes e variáveis intervenientes em um processo. Tendo em vista a distribuição espacial dos componentes e variáveis utilizadas, estruturou-se a aplicação da análise multicriterial em um sistema de informações geográficas (SIG).

Neste trabalho, adotou-se o sentido dado por Zêzere et al. (2004) para o termo suscetibilidade: "possibilidade espacial de ocorrência de um determinado fenômeno numa dada área com base em fatores condicionantes do terreno, independentemente do seu período de recorrência”. Destaquese, contudo, que muitas vezes têm-se empregado o termo risco para indicar o grau de suscetibilidade de uma certa área à ocorrência de fenômenos geológicos. A rigor, no entanto, para se obter o risco de ocorrência de dado fenômeno é necessário conhecer sua distribuição de probabilidades, ou “possibilidade temporal”, nas palavras de Zêzere et al. (2004).

\section{AVALIACCÃO DO GRAU DE SUSCETIBBILIDADE A FENỐMENOS GEOLÓGICOS}

A avaliação da suscetibilidade de um certo local a processos erosivos e movimentos de massa está diretamente relacionada aos fatores condicionantes desses processos. Assim, para avaliação da suscetibilidade à erosão dos solos pode-se empregar uma classificação baseada nas limitações das terras aos cultivos, a qual leva em conta fatores e restrições ligados ao tipo de solo, ao relevo, ao clima e ao tipo de cobertura vegetal. Em geral, combina-se o grau de limitação das terras devido à erosão com outros fatores/ restrições limitadores e obtêm-se, então, classes de capacidade ou de aptidão de uso das terras, como aquelas classes indicadas pelas metodologias descritas em Lepsch (1983) e Uberti et al. (1991), respectivamente. Aplicando-se esta última metodologia a uma certa área, por exemplo, a suscetibilidade à erosão pode ser inferida pela própria classe de aptidão de uso e, principalmente, pelo cruzamento entre classe de aptidão e uso atual das terras.

Ao contrário da erosão do solo, para avaliação da suscetibilidade a movimentos de massa não existe uma metodologia-modelo aplicável à variedade de situações possíveis. Existem, contudo, orientações que podem ser seguidas: uma ordenação dada por Cerri e Amaral (1998), por ilustração, mostra que para cada processo geológico devem ser identificadas as principais condições predisponentes, as in- 
tervenções antrópicas desencadeadoras e as feições de campo indicativas. Segundo os autores, para escorregamentos, por exemplo, as principais condições predisponentes são encostas com inclinação elevada, depósitos de tálus e coluviões, concentração do escoamento de águas superficiais e subsuperficiais e pluviometria média anual elevada, enquanto que as intervenções antrópicas desencadeadoras podem estar relacionadas à eliminação da cobertura vegetal, cortes desestabilizadores, lançamento de lixo e de água não controlados e à desestabilização de margens pela construção de reservatórios. Por sua vez, as feições indicativas podem ser trincas no terreno, degraus de abatimento e postes, árvores e muros inclinados ou tombados. Assim, para um dado local poderá ser obtida uma ponderação dessas variáveis para elaboração de um esquema qualitativo ou quantitativo de classificação da suscetibilidade local a escorregamentos. Observe-se, porém, a grande quantidade de informações necessárias à obtenção de uma classificação adequada, o que ocasiona problemas decorrentes da ausência de fontes em escala apropriada, custos e tempo para a realização dos trabalhos.

Alternativamente, é possível tomar o histórico do local para investigar a suscetibilidade a dado fenômeno geológico. O levantamento de ocorrências passadas e as devidas associações com os fatores desencadeadores podem ser suficientes para classificar uma certa localidade ou área em níveis de suscetibilidade ou mesmo de risco, caso seja possível estabelecer o tempo de recorrência e a magnitude dos eventos. As ocorrências passadas podem ser averiguadas a partir de cicatrizes de escorregamentos, como descrito em Soares et al. (2002), ou a partir de registros factuais, como no caso estudado em Ahrendt e Zuquette (2003), que analisaram fatores desencadeadores de escorregamentos em Campos do Jordão (SP) com base em eventos desse tipo ocorridos no início de 2000.

No caso que interessa a este trabalho, não havia registros recentes de escorregamentos, embora tenham sido identificadas na área de estudo cicatrizes e presença de colúvio, com evidências de pulsos sucessivos de erosão e transporte. De outra parte, a formação do lago da hidrelétrica adicionaria o fator desestabilização às encostas devido às alterações na cobertura vegetal, elevação do nível do lençol freático e aumento do escoamento superficial. Além disso, demandavase uma metodologia que englobasse suscetibilidade à erosão do solo e a movimentos de massa, processos distintos, embora por vezes associados. Portanto, a alternativa encontrada foi a elaboração de uma metodologia ad hoc que, ao final, combinasse uma seleção de fatores físicos desencadeadores dos processos com indicadores de eventos pregressos e com evidências de atividade presente. Optou-se, então, pela utilização da avaliação multicriterial suportada em Sistema de Informações Geográficas, discutida na seqüência do trabalho.

É importante destacar que, de acordo com classificação dada por Augusto Filho (1995), o método de avaliação utilizado no trabalho é do tipo superficial, pois foi composto por estudos pedológicos, vistorias de campo e levantamentos topográficos/fotogramétricos. O estudo serviu, posteriormente, para indicar alguns locais de maior suscetibilidade destinados a monitoramento intensivo, utilizando-se, neste caso, um método que pode ser enquadrado como subsuperficial direto na classificação de Augusto Filho (1995), pois é constituído por instalação de marcos topográficos em encostas classificadas como de alta suscetibilidade a processos erosivos/ escorregamentos, gerando medições periódicas da posição desses marcos com instrumento de precisão (estação total).

\section{AVALIAÇÃO MULTICRITERIAL}

No Brasil, a precipitação pluviométrica é reconhecida como o principal agente deflagrador ("gatilho") dos processos de erosão e movimentos de massa, mas os efeitos observados estão fortemente ligados às características físicas do meio e à associação dessas características com ações antrópicas, geralmente ocupações de encostas íngremes com lavouras, pastagens ou moradias. Uma vez que diversos elementos intervêm nesses processos, para a identificação de áreas suscetíveis deve-se dispor de alternativas para combiná-los de forma coerente. Para casos assim delineados, a abordagem da avaliação multicriterial é uma opção adequada para apoiar a tomada de decisão. A seguir são apresentadas algumas definições sobre esse tipo de abordagem retiradas e adaptadas de Eastman et al. (1995).

Para avaliar a suscetibilidade de uma dada área, há possibilidades que devem ser consideradas e ponderadas no sentido de amparar a tomada de decisão, que nada mais é do que uma "escolha entre alternativas”. Essas alternativas, por sua vez, levam em conta diferentes ações em curso, diferentes hipóteses acerca das características de um elemento, diferentes classificações etc. Esse conjunto de alternativas compõe um “quadro de decisão”, que, em sua forma definitiva, poderá conter opções tais como "suscetibilidade alta, suscetibilidade média, suscetibilidade baixa”.

Para a tomada de decisão são requeridos critérios, aqui considerados como bases mensuráveis ou passíveis de avaliação para comparação, julgamento ou apreciação de coisas, pessoas ou valores. Seguindo a abordagem proposta por Eastman et al. (1995), os critérios podem ser de dois tipos: fatores e restrições. Um fator é um critério que melhora ou piora uma alternativa específica associada ao problema-alvo, devendo ser medido em escala contínua. Por sua vez, uma restrição é um critério que limita as alternativas consideradas e geralmente atua por exclusão. Para o problema-alvo deste trabalho podem ser enumerados diversos fatores, como a declividade, por exemplo, variável naturalmente medida em escala contínua e que está diretamente associada ao aumento/diminuição da suscetibilidade a processos geológicos. Em 
contrapartida, um exemplo típico de restrição para a área de estudo poderia ser a presença de processo ativo de movimento de massa: note-se que, nesse caso, todos os outros fatores podem ser considerados desnecessários para a tomada de decisão e, dessa forma, a restrição atuaria como limitadora (apesar de nesse caso o termo restrição parecer forçado, ele tem o mesmo significado de uma limitação qualquer para uso agrícola do solo como, por exemplo, limitações devido às áreas de preservação permanente e reserva legal).

Definidos os critérios, o passo seguinte é estabelecer uma “regra de decisão”, que constitui o procedimento pelo qual os critérios são combinados para se chegar a uma avaliação particular. Regras de decisão podem variar desde simples limiares aplicados a um único critério (tal como considerar áreas críticas à erosão aquelas que possuem declividade acima de 35\%) até complexas comparações que envolvem múltiplos critérios. Uma regra de decisão é estruturada no contexto de um objetivo específico, caso geral, ou para atender multiobjetivos, e pode ser de dois tipos fundamentais:

1. decisão baseada em avaliação de hipóteses alternativas acerca de elementos individuais;

2. decisão sobre a inclusão ou não de elementos em um conjunto. No primeiro tipo, a decisão resulta em uma classificação, enquanto que no segundo chega-se a uma seleção.

O problema abordado neste trabalho é claramente identificado como uma classificação voltada a um objetivo determinado.

\section{SELEÇÃO DE CRITÉRIOS}

Em usinas hidrelétricas pode ocorrer uma diminuição da estabilidade das encostas marginais ao lago formado pela represa, principalmente no "entorno das elevações correspondentes à faixa de variação operacional do nível d’água e nas áreas imediatamente acima do nível do reservatório”, de acordo com descrito por Oliveira (1998). Além disso, outro problema é o assoreamento progressivo do reservatório, decorrente principalmente da erosão de solos cultivados na bacia contribuinte.

Na situação de estudo, os critérios gerais relevo, solo e cobertura do solo foram julgados como os de maior relevância. Seguindo a tipificação estabelecida por Eastman et al. (1995), cada critério geral pode ser subdividido em fatores e restrições, mas, no contexto do trabalho, verificou-se a necessidade de subdividi-los apenas em fatores (contudo, incluiu-se um critério do tipo restrição ao final do processo de obtenção das classes de suscetibilidade, como se verá). Dessa forma, subdividiu-se o critério relevo em quatro fatores: geomorfologia, declividade, comprimento dos pendentes e orientação das vertentes; o critério solo, em cinco fatores: drenagem interna do perfil, profundidade, textura, pedregosidade e retenção subsuperficial de água; para o critério cobertura, por sua vez, adotaram-se dois fatores: tipo de cobertura e densidade.

Na seqüência, cada fator recebeu um conjunto de características indicadoras, ordenadas segundo a propensão a processos erosivos e movimentos de massa. Essas características indicadoras podem expressar qualidades do fator, como, por exemplo, solo bem/mal drenado, ou podem expressar tipos, como os diferentes tipos de coberturas do solo. Para obtenção do grau de suscetibilidade de cada fator, a escala ordinal das características indicadoras foi alterada para cardinal, atribuindo-se valores entre zero e um a cada uma delas, indicando, respectivamente, efeito máximo até nenhum efeito na manifestação de processos erosivos e/ou movimentos de massa. Os critérios, fatores e características estão listados na Tabela 1, juntamente com a escala numérica (cardinal) utilizada. A cada fator é possível atribuir uma importância relativa, representada pelos pesos exibidos na última coluna da Tabela 1. Pode-se observar que o somatório dos pesos é igual a 1, distribuídos do seguinte modo: 0,42 (42\%) para o critério relevo; 0,24 (24\%) para solos; e 0,34 (34\%) para cobertura (usos) do solo. Considerando-se todos os fatores, o de maior peso é o tipo de cobertura $(0,22)$, seguido da declividade $(0,19)$, geomorfologia $(0,17)$ e densidade da cobertura vegetal $(0,12)$. Os fatores de solo apresentam pesos relativos mais baixos, pois eles assumem maior importância quando combinados principalmente com os fatores de relevo (solo vs. declividade, por exemplo).

A escala numérica utilizada para ordenar as características indicadoras, bem como os pesos dos fatores, pode ser obtida por meio de consenso técnico. Opcionalmente, para atribuição dos pesos pode-se fazer uso de técnicas específicas. No presente estudo, utilizou-se uma técnica de comparação em que cada fator foi confrontado com todos os outros (pairwise comparisons), atribuindo-se um grau de importância segundo uma escala pré-definida. Esta técnica para obtenção de pesos está descrita em detalhes em Eastman et al. (1995) e também em Ferraz e Vettorazzi (2003).

\section{ÁREA DE ESTUDO E MÉTODOS EMPREGADOS NA IDENTIFICAÇÃO E CARACTERIZAÇÃOO DOS FATORES}

A avaliação da suscetibilidade a processos erosivos e movimentos de massa discutida neste trabalho foi aplicada no entorno da usina hidrelétrica (UHE) Quebra-Queixo, localizada em trecho do rio Chapecó entre os municípios catarinenses de São Domingos (margem direita) e Ipuaçu (margem esquerda), conforme pode ser visualizado na Figura 1. A título de informação geral, na Tabela 2 são listadas algumas características básicas da usina hidrelétrica alvo do estudo. 


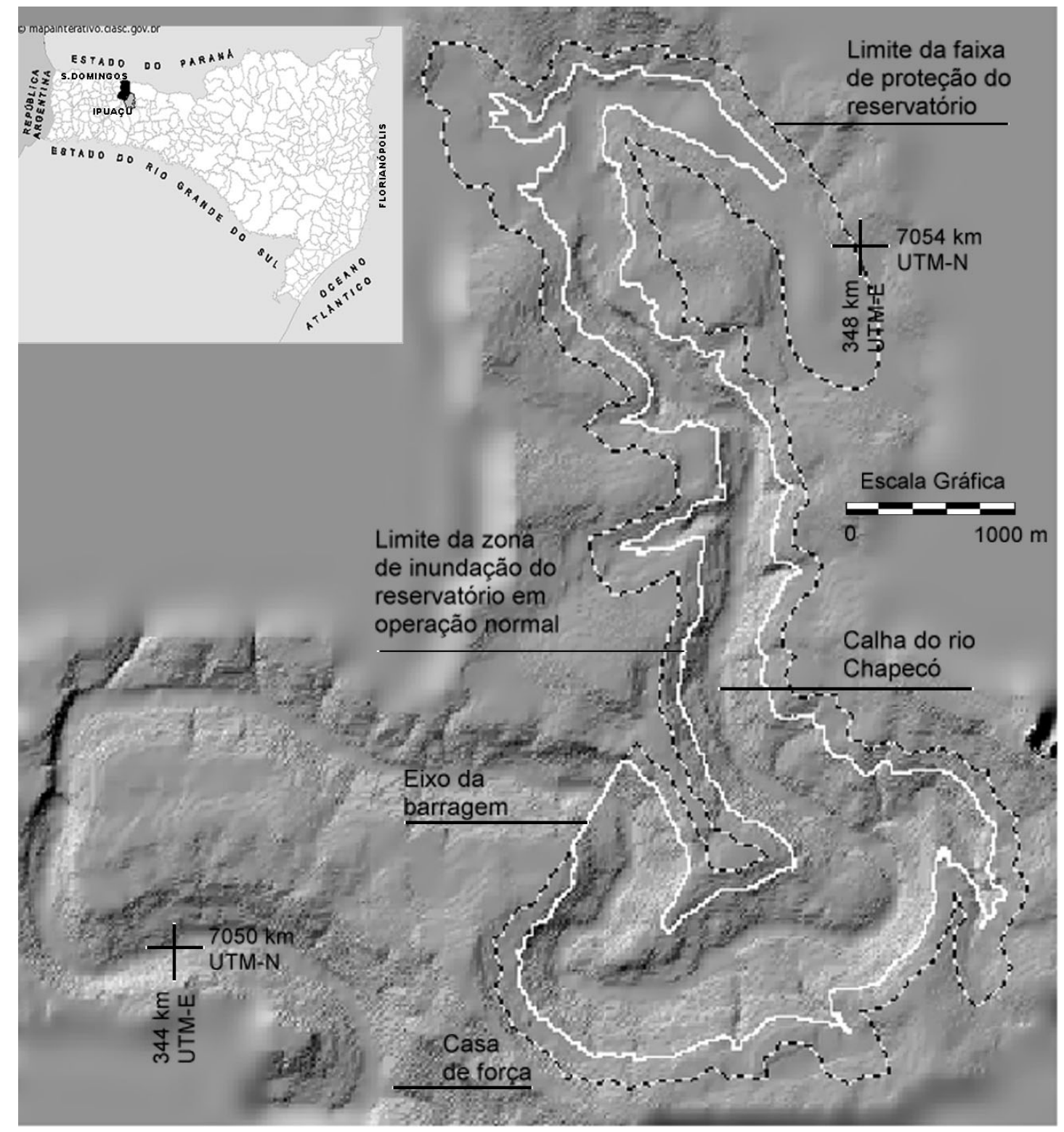

Figura 1. Localização da usina hidrelétrica de Quebra-Queixo, municípios de São Domingos (margem direita) e Ipuaçu (margem esquerda), Santa Catarina. Em destaque apresenta-se modelo digital de terreno do local da usina com sombreamento de relevo, ângulo azimutal solar de $315^{\circ}$, elevação acima do horizonte de $35^{\circ}$, sem exagero vertical. 
Os métodos aplicáveis a cada situação de investigação podem variar conforme a escala do trabalho, disponibilidade de informações e recursos técnico-financeiros disponíveis. A seguir, de modo sucinto, são listados os principais procedimentos empregados na caracterização dos fatores relacionados na Tabela 1:

1. Critério relevo: as unidades de cobertura superficiais remobilizadas e cobertura autóctone do fator geomorfologia foram obtidas de forma preliminar por meio de fotointerpretação em aerofotos escala 1:20.000 e posteriormente foram verificadas por inspeção a campo. As coberturas remobilizadas foram definidas como todo e qualquer material resultante da transformação das rochas por processos de alteração, que tenha sofrido transporte e deposição ao longo do tempo através de processos naturais ou induzidos por atividades humanas. Os fatores “declividade”, “comprimento das vertentes” e "orientação das vertentes” foram caracterizados empregando-se um modelo digital do terreno (MDT) gerado a partir da digitalização de curvas de nível com eqüidistância de $20 \mathrm{~m}$ traçadas em carta geográfica 1:50.000 (Ministério do Exército, 1980). Os procedimentos para geração do MDT e obtenção das declividades, orientação das vertentes e comprimentos dos pendentes foram realizados no SIG Idrisi ${ }^{\circledR}$ (1997). Todos esses planos de informação foram criados em estrutura matricial (raster), com resolução espacial de 30 x $30 \mathrm{~m}$.

2. Critério solo: a caracterização pedológica foi realizada por fotointerpretação aérea (aerofotos escala 1:20.000), obtendo-se legenda preliminar, e por verificação a campo - pelo método de caminhamento, tradagens e descrição de perfis.

3. Critério cobertura superficial: obteve-se o tipo de cobertura em mapa dos usos do solo (escala 1:10.000) existente para a área de estudo. A densidade da cobertura foi avaliada a partir de imagens Landsat TM5, aplicando-se a técnica digital denominada “índice de vegetação” (empregouse o módulo NDVI - índice de vegetação por diferenças normalizadas - incluído no SIG Idrisi $\left.{ }^{\circledR}, 1997\right)$.

\section{SISTEMA DE INFORMAÇÕES GEOGRÁFICAS E AVALIAÇÃO MULTICRITERIAL}

Como os critérios e fatores utilizados na avaliação multicriterial são tipicamente distribuídos no espaço, uma alternativa adequada para estudá-los é o emprego de geoprocessamento, que pode ser definido como "tecnologia voltada à coleta e tratamento de informações espaciais para um objetivo determinado”. As atividades que envolvem geoprocessamento podem ser executadas por sistemas específicos elaborados para cada aplicação, envolvendo principalmente dispositivos e técnicas computacionais. Estes sistemas são denominados Sistemas de Informações Geo- gráficas (SIG), conceituado por Burrough (1986) como “um conjunto de ferramentas para coleta, armazenamento, recuperação, transformação e exibição de dados espaciais oriundos do mundo real e destinados a propósitos específicos”.

Os procedimentos para distribuição espacial dos critérios, atribuição de escores ponderados aos fatores e combinação final podem ser realizados em um SIG, com cada fator tomando a forma de um plano de informação (PI) ou layer individual. Esta forma de representação é própria dos SIGs e consiste em um espaço multidimensional como apresentado na Figura 2.

Em um SIG, os dados podem ser estruturados em formato vetorial ou raster. Em raster, forma de estrutura na qual se baseia o SIG Idrisi ${ }^{\circledR}$ (1997), a unidade de um mapa é denominada célula ou pixel e cada uma delas é referenciada segundo um sistema de coordenadas - coordenadas geográficas, por exemplo. A área que cada célula representa é dada pela resolução espacial dos PIs, adotada segundo a resolução dos dados originais utilizados como entrada ou mesmo por conveniências práticas. Por exemplo, quando se utilizam PIs compostos por imagens de sensoriamento remoto adquiridas pelo sistema Landsat TM5 ou ETM7, fornecidas com resolução espacial de 30 x 30 m $\left(900 \mathrm{~m}^{2}\right)$, geralmente mantém-se esta resolução para os demais PIs empregados na análise. No trabalho, apesar de algumas fontes de dados apresentarem escala de 1:10.000 (mapa de vegetação) ou escala 1:20.000 (aerofotos), optou-se pela resolução espacial de 30 x 30 m devido sua compatibilidade com os dados de satélite Landsat TM5 e carta geográfica escala 1:50.000 (utilizados para obtenção da densidade da vegetação e modelo digital do terreno, respectivamente).

A partir dos PIs pode-se obter o conjunto de informações associadas a uma certa célula, como está ilustrado na Figura 3. Dessa forma, ao conjunto de informações relacionadas aos fatores listados na Tabela 1 podem ser aplicadas operações matemáticas destinadas à obtenção, para cada fração do espaço representada por uma célula, do grau de suscetibilidade global para ocorrência de processos erosivos e movimentos de massa.

Uma questão chave na decisão multicriterial é como tratar as informações provenientes de diversos critérios/fatores de modo a formar um único índice de avaliação. Em cada fator tratado isoladamente, para avaliar o risco basta tomar seu “escore” - atribuído com base em uma escala numérica contínua utilizada para enquadrar cada característica. Tomem-se as informações da Tabela 1, por exemplo: quando o relevo for “escarpado" (declividade maior do que 75\%), o escore = 0,00 representado na escala indica que o grau de suscetibilidade é máximo nesse fator. Por sua vez, quando o relevo for considerado plano ( 0 - 3\% de declividade), o escore $=0,90$ indica que a suscetibilidade para ocorrência de processos erosivos e movimentos de massa é mínima (mas não nula). 
Tabela 1. Critérios, fatores e características indicadoras adotadas na classificação de locais quanto a suscetibilidade a processos erosivos e movimentos de massa. UHE Quebra-Queixo, bacia do rio Chapecó, municípios de São Domingos e Ipuaçu, SC.

\begin{tabular}{|c|c|c|c|c|}
\hline \multirow{18}{*}{ 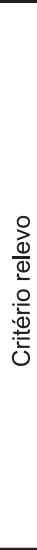 } & Fatores & Características indicadoras & Escala & Peso \\
\hline & \multirow{6}{*}{$\begin{array}{l}\text { Geomorfológicos } \\
\text { (cobertura autóctone e unidades } \\
\text { superficiais remobilizadas) }\end{array}$} & Cobertura autóctone & 0,95 & \multirow{6}{*}{0,17} \\
\hline & & Depósito calha-alúvio/colúvio & 0,90 & \\
\hline & & Movimentos translacionais & 0,60 & \\
\hline & & Colúvio regularizado & 0,40 & \\
\hline & & Movimento de massa profundo & 0,30 & \\
\hline & & Alúvio/colúvio & 0,20 & \\
\hline & \multirow{6}{*}{ Declividade } & Plano $(0-3 \%)$ & 0,90 & \multirow{6}{*}{0,19} \\
\hline & & Suavemente ondulado $(3-8 \%)$ & 0,75 & \\
\hline & & Ondulado $(8-25 \%)$ & 0,60 & \\
\hline & & Fortemente ondulado (25 - 45\%) & 0,40 & \\
\hline & & Montanhoso (45 - 75\%) & 0,20 & \\
\hline & & Escarpado $(>75 \%)$ & 0,00 & \\
\hline & \multirow{3}{*}{ Comprimento dos pendentes } & Curto & 0,66 & \multirow{3}{*}{0,05} \\
\hline & & Médio & 0,33 & \\
\hline & & Longo & 0,00 & \\
\hline & \multirow{2}{*}{ Orientação das vertentes } & Opostas aos talvegues principais & 0,50 & \multirow{2}{*}{0,01} \\
\hline & & Orientadas para os talvegues principais & 0,00 & \\
\hline \multirow{17}{*}{ 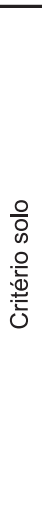 } & \multirow{3}{*}{ Drenagem interna } & Bem drenado & 0,75 & \multirow{3}{*}{0,03} \\
\hline & & Imperfeitamente drenado & 0,50 & \\
\hline & & Mal drenado & 0,25 & \\
\hline & \multirow{4}{*}{ Profundidade } & Muito profundos & 0,75 & \multirow{4}{*}{0,05} \\
\hline & & Profundos & 0,50 & \\
\hline & & Médios & 0,25 & \\
\hline & & Rasos & 0,00 & \\
\hline & \multirow{4}{*}{ Textura } & Muito argilosa & 0,75 & \multirow{4}{*}{0,06} \\
\hline & & Argilosa & 0,50 & \\
\hline & & Média & 0,25 & \\
\hline & & Arenosa & 0,00 & \\
\hline & \multirow{3}{*}{ Pedregosidade } & Ausente & 1,00 & \multirow{3}{*}{0,02} \\
\hline & & Moderada & 0,50 & \\
\hline & & Forte & 0,00 & \\
\hline & \multirow{3}{*}{ Retenção subsuperficial de água } & Baixa & 0,75 & \multirow{3}{*}{0,08} \\
\hline & & Média & 0,50 & \\
\hline & & Alta & 0,00 & \\
\hline \multirow{12}{*}{ 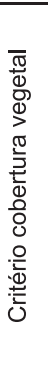 } & \multirow{8}{*}{ Tipo de cobertura } & Mata & 0,85 & \multirow{8}{*}{0,22} \\
\hline & & Reflorestamento & 0,80 & \\
\hline & & Capoeira & 0,65 & \\
\hline & & Capoeirinha & 0,50 & \\
\hline & & Campo & 0,35 & \\
\hline & & Banhados & 0,15 & \\
\hline & & Cultivos & 0,10 & \\
\hline & & Solo descoberto & 0,00 & \\
\hline & & Alta & 0,80 & \\
\hline & & Média & 0,50 & \\
\hline & Densidade da cobertura & Baixa & 0,20 & 0,12 \\
\hline & & Nula & 0,00 & \\
\hline
\end{tabular}

Tabela 2. Características básicas da usina hidrelétrica de Quebra-Queixo, rio Chapecó, municípios de São Domingos e Ipuaçu, SC. Fonte: Engevix (1997).

\begin{tabular}{lr}
\hline Característica & Valores \\
\hline Potência instalada & $120,0 \mathrm{MW}$ \\
Energia assegurada & $59,7 \mathrm{MW}$ \\
Área de drenagem (a partir do eixo da barragem) & $2.670 \mathrm{~km}^{2}$ \\
Nível médio da água a montante & $549,0 \mathrm{~m}$ \\
Nível médio da água a jusante & $426,5 \mathrm{~m}$ \\
Queda bruta máxima & $123,9 \mathrm{~m}$ \\
Área inundada (nível da água máximo maximorum) & $6,73 \mathrm{~km}^{2}$ \\
Área inundada (nível da água máximo normal) & $5,60 \mathrm{~km}^{2}$ \\
Crista da barragem & $672 \mathrm{~m}$ \\
Altura máxima da barragem & $75 \mathrm{~m}$ \\
\hline
\end{tabular}


célula 1:

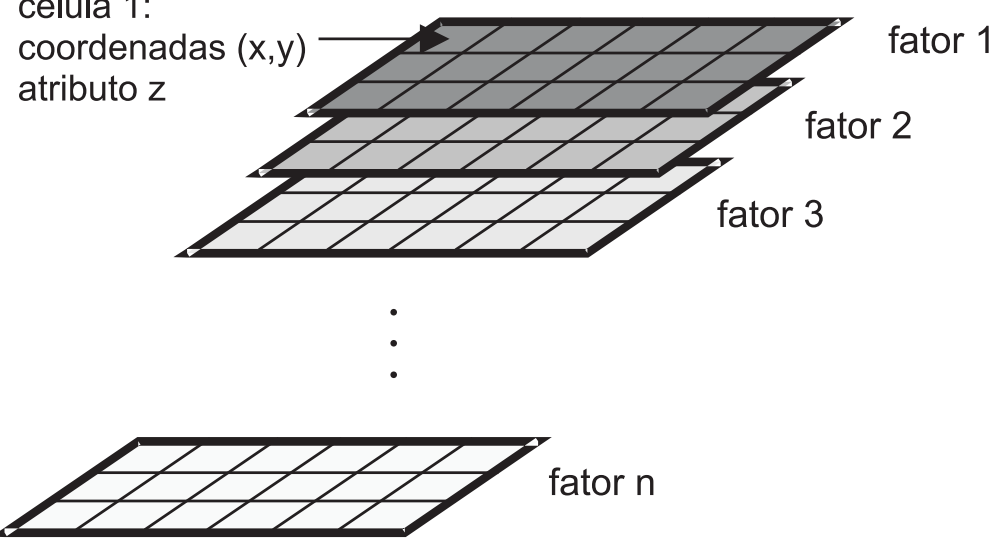

Figura 2. Representação em SIG de fatores (atributos espaciais) em planos de informações (Pls) ou layers. Adaptado de Burrough (1986).
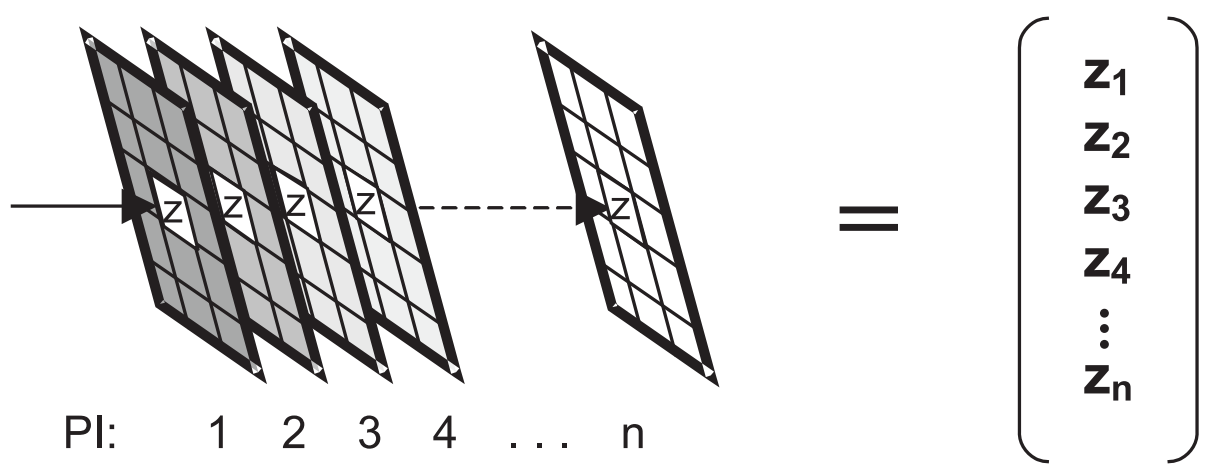

Figura 3. Esquema da operação para extração dos atributos $z(1,2, \ldots, n)$ a partir de uma série de planos de informação $[\mathrm{PI}(1,2, \ldots, n)]$. Adaptado de Burrough (1986). 
Para tratar todos os fatores, com seus respectivos escores e pesos, empregou-se uma combinação linear ponderada dada pela expressão:

$$
S=1-\left(\sum_{i=1}^{n} w_{i} x_{i}\right)
$$

onde: $\mathbf{S}=$ suscetibilidade final;

$\mathbf{w}_{\mathrm{i}}=$ peso do fator $\mathrm{i}$;

$\mathbf{x}_{\mathrm{i}}=$ escore do fator $\mathrm{i}$;

$\mathbf{n}=$ número de fatores.

Em cada porção do terreno da área de estudo (célula de 30 x 30 m ou $900 \mathrm{~m}^{2}$ ), a equação (1) toma os 11 escores parciais referentes aos fatores, os pondera pelos respectivos pesos e faz o somatório final. O artifício de subtrair da unidade o somatório obtido é feito apenas para manter a identidade de quanto mais próximo de 1, maior a suscetibilidade à erosão e movimentos de massa. Para obtenção da suscetibilidade final em uma certa área, então, aplica-se a equação (1) a todas as células em que a área foi subdividida. Portanto, o resultado deverá ser um plano de informação ou mapa final que contenha em cada célula um valor único que indique a suscetibilidade para ocorrência de processos erosivos e movimentos de massa. Ou seja, o resultado a ser obtido deverá ser uma distribuição espacial dos graus de suscetibilidade, que assumem valores entre zero (suscetibilidade nula) e um (suscetibilidade máxima).

Em algumas situações, certos locais podem apresentar sinais que evidenciam por si processos erosivos e presença de movimentos de massa. Esses sinais podem ser, por exemplo, ravinamentos, fraturas, falhas, presença de depósitos de materiais, inclinações de árvores e postes, entre outros. Em tais casos, os critérios enquadrados como fatores passam a ser secundários. Para acomodar esses sinais, introduz-se na equação (1) uma restrição, conforme abaixo:

$$
S=1-\left[\left(\sum_{i=1}^{n} w_{i} x_{i}\right) * c_{j}\right]
$$

onde: $\mathbf{C}_{\mathbf{j}}=$ valor da restrição $\mathbf{j}$.

No limite, a restrição $C_{j}$ poderá assumir o valor zero, indicando a presença de um sinal que torna a suscetibilidade máxima, ou um $(1,0)$, quando não houver sinais. Neste último caso, fica claro que a equação (2) torna-se igual à equação (1). Deve-se notar, no entanto, que o uso desse tipo de restrição apenas é conveniente quando da possibilidade de existirem sinais pontuais que não podem ser enquadrados dentro dos fatores previamente selecionados. Na situação de estudo, a aplicação de restrições não foi necessária.

\section{RESULTADOS OBTIDOS E LIMITAÇÕES DO MÉTODO}

O produto obtido com o método constituiu uma avaliação espacial do grau de suscetibilidade a processos erosivos e de movimentos de massa da área marginal ao lago da usina hidrelétrica de Quebra-Queixo. Essa avaliação está representada sob a forma de um mapa temático contendo classes de suscetibilidade, como exibido na Figura 4. Nela pode-se observar que a área de investigação ficou subdividida em três classes: suscetibilidade alta, moderada e baixa. Tais classes serviram como base preliminar para investigações mais intensivas no entorno da hidrelétrica e também para orientar ações preventivas específicas, como manejo da vegetação presente na área e recomposição vegetal das encostas.

Em termos quantitativos, a área total de aplicação do método englobou aproximadamente $11,5 \mathrm{~km}^{2}$, incluindo área alagada, faixa de proteção de $100 \mathrm{~m}$ além da cota de inundação normal e dos locais situados a jusante do reservatório e sujeitos à intervenção durante as obras. A maior parte dessa área (8,5 km² ou 74\% do total) foi enquadrada na classe de suscetibilidade moderada, enquanto que as classes de suscetibilidade baixa e alta ocuparam áreas similares, em torno de $1,5 \mathrm{~km}^{2}$ cada ou $13 \%$ do total. Quanto à localização das classes, pela Figura 4 pode-se notar que a maior parte da área com alta suscetibilidade à erosão e movimentos de massa situa-se na região inundada. Isso se deve fundamentalmente ao fato de o rio Chapecó originalmente ser muito encaixado naquele trecho, determinando altos gradientes topográficos entre o leito e as margens.

De posse do mapa temático, foram selecionados locais em áreas de suscetibilidade alta para vistorias periódicas ao longo das fases de implantação do empreendimento (obras de engenharia pesada), formação do reservatório e operação da usina. Esses locais foram denominados de pontos de acompanhamento, quando destinados a inspeções qualitativas (sem instrumentação), e pontos de monitoramento, quando realizadas medições quantitativas (basicamente medição de eventual deslocamento de marcos topográficos). A freqüência das inspeções foi moderada na implantação do empreendimento (mensal ou bimestral), alta na fase crítica de enchimento do reservatório (semanal) e gradativamente mais baixa na fase operacional. Essas inspeções atualmente ainda estão em curso, em freqüência semestral.

No tocante ao apoio de ações específicas, o mapa temático obtido permitiu orientar as tarefas de corte e destocamento da vegetação arbórea localizada na área de inundação. As porções adjacentes às margens e em classe de alta suscetibilidade foram mantidas com a vegetação original ou apenas sofreram desbaste, sem destocamento. Assim, dado que a ausência de vegetação ampliaria o grau 


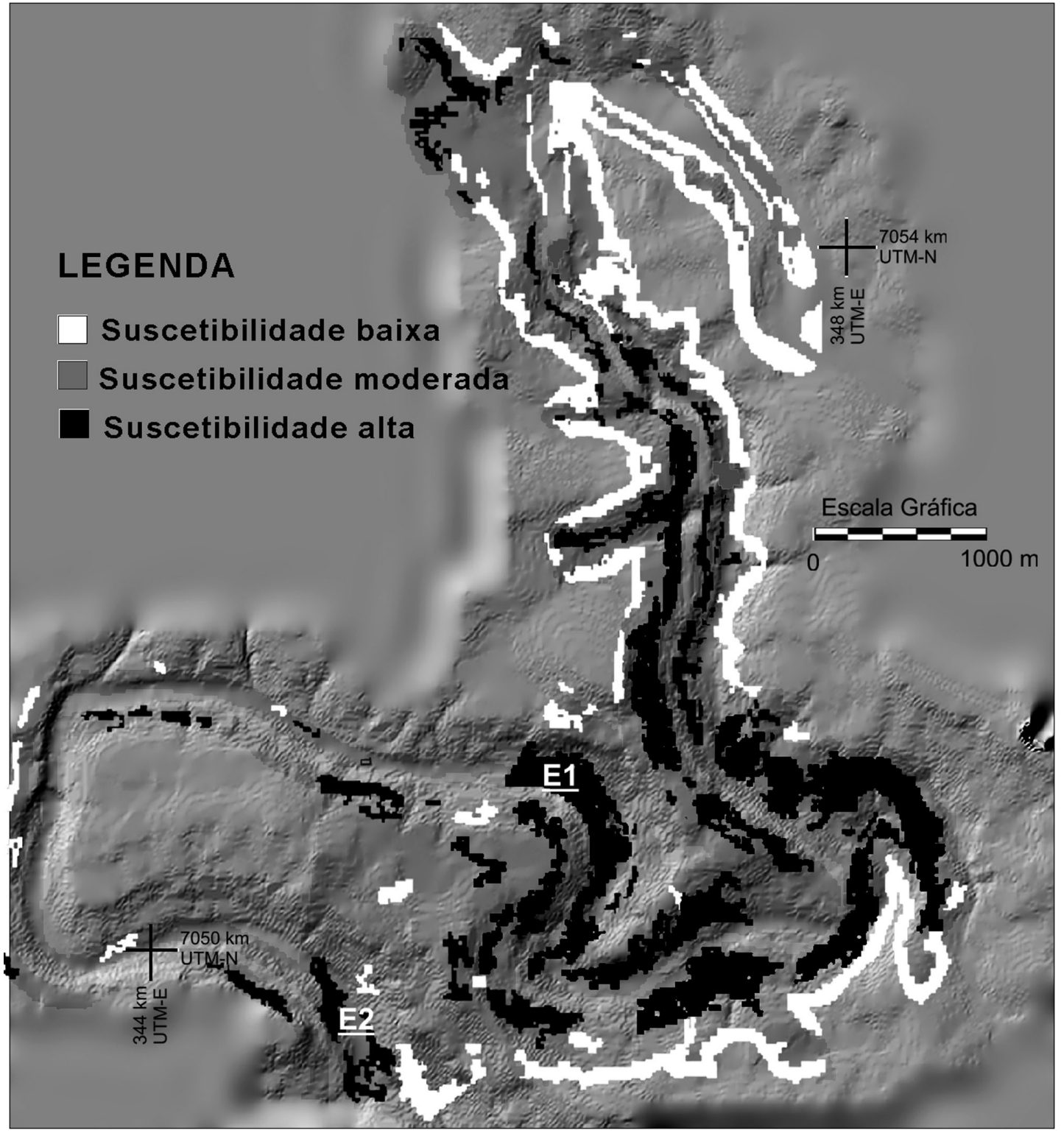

Figura 4. Classes de suscetibilidade a processos erosivos e movimentos gravitacionais de massa na área do aproveitamento hidrelétrico Quebra Queixo, municípios de São Domingos e Ipuaçu (SC). Base: modelo digital de terreno com sombreamento de relevo, ângulo azimutal solar de $315^{\circ}$, elevação acima do horizonte de $35^{\circ}$, sem exagero vertical. Os pontos E1 e E2 indicam locais onde ocorreram deslizamentos recentes. 
de suscetibilidade à erosão e movimentos de massa, o órgão ambiental permitiu que em tais porções inundáveis ela fosse preservada.

Ao longo do período de monitoramento ocorreram dois eventos significativos de movimentos de massa nas margens do reservatório: um deles junto à ombreira direita do eixo da barragem e outro, mais recente, em área a jusante do eixo, próximo à casa de força (pontos E1 e E2 na Figura 4). O primeiro evento consistiu em um movimento de terra e rocha e deuse em local naturalmente crítico (alta suscetibilidade), adjacente a um ponto em que se executavam obras de engenharia pesada. Dada a extensão do evento e suas implicações à própria estabilidade do maciço, foram necessárias obras de contenção da encosta e drenagem superficial da área. A Figura 5 exibe um registro fotográfico desse local. O segundo evento, um escorregamento menos intenso do que o anterior, ocorreu em encosta adjacente à estrada para a casa de força. Também neste caso o fator preponderante para manifestação do problema foi a intervenção antrópica em área definida como de alta suscetibilidade.
Portanto, deve-se apontar que a principal limitação do método aplicado foi justamente não ter sido incluído um fator ou restrição do tipo “grau de intervenção antrópica” ou similar. Justifica-se esta falha pelo fato de o método ter sido aplicado a priori, antes de serem conhecidos os locais sujeitos às obras mais intensivas. Em eventuais aplicações futuras similares, essa falha poderá ser facilmente corrigida pela inclusão de um fator que ajusta o grau de intervenção devido a obras de engenharia, tráfego de máquinas, detonações etc.

Limitações adicionais decorrem principalmente do fato de o método exigir grande quantidade de informações, que nem sempre estão disponíveis e em geral possuem custo relativamente elevado para serem obtidas. Além disso, o método requer implementação em sistemas de informações geográficas, tecnologias especializadas exigentes em equipamentos e na capacitação dos usuários. No entanto, tais dificuldades tendem a diminuir devido à crescente utilização das técnicas digitais para obtenção e tratamento de dados espaciais, o que tem ampliado a oferta de informações geográficas georreferenciadas.

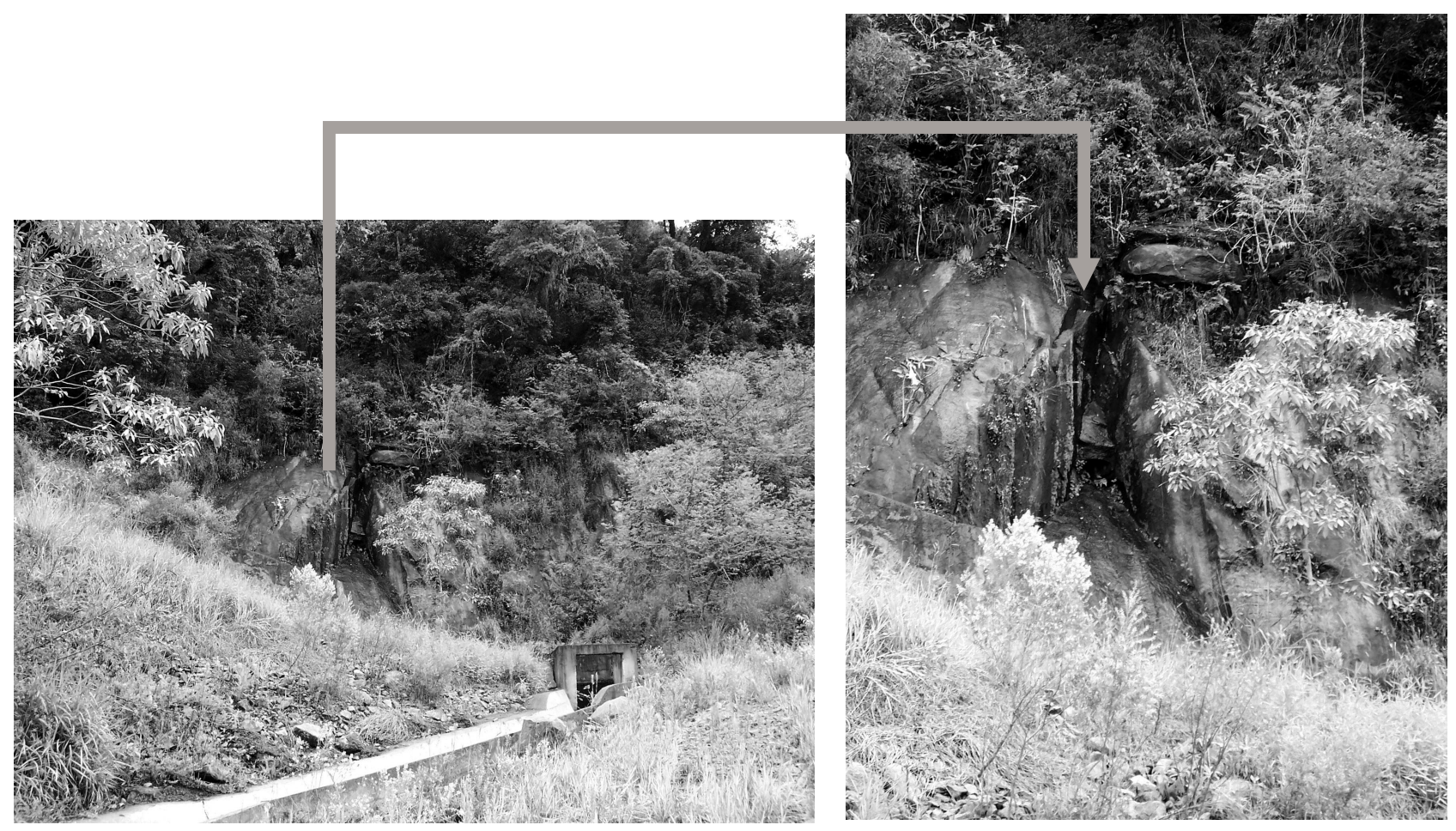

Figura 5. Registros fotográficos de local em que ocorreu deslizamento de terra, situado junto à ombreira direita do eixo da barragem da UHE Quebra-Queixo, municípios de São Domingos e Ipuaçu (SC). O evento ocorreu em 2002. 


\section{AGRADECIMENTOS}

Os autores agradecem ao Engenheiro Agrônomo Marcos Krieger, da ETS - Energia, Transporte e Saneamento S/C Ltda, pelo convite para realização deste trabalho e pelas diversas colaborações, e aos revisores anônimos, que fizeram correções e acréscimos fundamentais ao texto.

\section{REFERÊNCIAS BIBLIOGRÁFICAS}

AHRENDT, A.; ZUQUETTE, L. V. Triggering factors of landslides in Campos do Jordão city, Brazil. Bulletin of Engineering Geology and the Environment, v. 62, p. 231-244, 2003.

AUGUSTO FILHO, O. Escorregamentos em encostas naturais e ocupadas: análise e controle. In:. BITAR, O. Y. (Coord.). Curso de geologia aplicada ao meio ambiente. São Paulo: ABGE - Associação Brasileira de Geologia de Engenharia, 1995. p. 77-100.

AUGUSTO FILHO, O.; VIRGILI, J. C. Estabilidade de taludes. In: OLIVEIRA, A. M. S.; BRITO, S. N. A. Geologia de engenharia. São Paulo: ABGE, 1998. p. 243-269.

BIGARELLA, J. J. Estrutura e origem das paisagens tropicais e subtropicais. Florianópolis: UFSC, 2003.

BURROUGH, P. A. Principles of geographical information systems for land resources assessment. New York: Oxford University Press, 1986. 194 p. (Monographs on Soil and Resources Survey, n. 12).

CERRI, L. E. da S.; AMARAL, C. P. do. Riscos geológicos. In: OLIVEIRA, A. M. S.; BRITO, S. N. A. Geologia de engenharia. São Paulo: ABGE, 1998. p. 301-310.

EASTMAN, J. R.; JIN, W.; KYEM, P. A. K.; TOLEDANO, J. Raster procedures for multi-criteria/multi-objective decisions. Photogrammetric Engineering \& Remote Sensing, v. 61, n. 5, p. 539-547, 1995.

ENGEVIX. Estudos de Impacto Ambiental - UHE Quebra Queixo. Rio de Janeiro, 1997.

FERNANDES, N. F.; AMARAL, C. P. do. Movimentos de massa: uma abordagem geológico-geomorfológica. In: GUERRA, A.T.; CUNHA, S. B. Geomorfologia e meio ambiente. Rio de Janeiro: Bertrand Brasil, 1996. p. 123-194.

FERRAZ, S. F. de B.; VETTORAZZI, C. A. Identificação de áreas para recomposição florestal com base em princípios de ecologia de paisagem. Revista Árvore, v. 27, n. 4, p. 575-583, 2003.

IDRISI ${ }^{\circledR}$. Idrisi for Windows, Version 2.0. Clark Labs for Cartographic Technology and Geographic Analysis. Worcester, MA : Clark University, 1997.

LEPSCH, I. F. (Coord.). Manual para levantamento utilitário do meio físico e classificação de terras no sistema de capacidade de uso, $4^{\mathrm{a}}$ aproximação. Campinas: Sociedade Brasileira de Ciência do Solo, 1983. 175 p.

MARQUES FILHO, P. L.; GERALDO, A. Barragens e reservatórios. In: OLIVEIRA, A. M. S.; BRITO, S. N.A. Geologia de engenharia. São Paulo: ABGE, 1998. p. 397-418.

MINISTÉRIO DO EXÉRCITO. Departamento de Engenharia e Comunicações. Diretoria de Serviço Geográfico. Folha São Domingos-SC, SG-22-Y-A-VI-2 MI-2874/2, 1980. Escala 1:50.000.

SOARES, P. C.; SOARES, A. P.; FIORI, A. P. Raciocínio probabilístico aplicado à suscetibilidade de escorregamentos: um estudo de caso em Campo Largo, Paraná, Brasil. Boletim Paranaense de Geociências, v. 50, p. 61-76, 2002.

UBERTI,A.A.A.; BACIC, I. L. Z.; PANICHI, J. deA.V.; LAUS NETO, J.A.; MOSER, J. M.; PUNDEK, M.; CARRIÃO, S. L. Metodologia para classificação da aptidão de uso das terras do Estado de Santa Catarina. Florianópolis: EMPASC/ ACARESC, 1991.19p. (EMPASC. Documentos, 119).

ZÊZERE, J. L.; RODRIGUES, M. L.; REIS, E.; GARCIA, R.; OLIVEIRA, S.; VIEIRA,G.; FERREIRA, A. B. Spatial and temporal data management for the probabilistic landslide hazard assessment considering landslide typology. In: LACERDA, W. A.; EHRLICH, M.; FONTOURA, S. A. B.; SAYÃO, A. S. F. (Ed). Landslides: evaluation \& stabilization. Londres: Taylor \& Francis Group, 2004. p. 117-123. 